\title{
Irritable Bowel Syndrome and Antidepressants
}

\author{
Frederic R. Curtiss, PhD, RPh, CEBS
}

$I^{n}$ this issue of JMCP, Faresjö and colleagues found that 13.3\% of patients with irritable bowel syndrome (IBS) reported using antidepressants versus $4.5 \%$ of control patients without IBS. ${ }^{1}$ The more than 3-fold higher use of antidepressants (odds ratio $[\mathrm{OR}]=3.27,95 \%$ confidence interval $[\mathrm{CI}]=2.27-4.70$ ) among patients with IBS is not a surprising finding, but the actual use of drugs by IBS patients is little studied despite the high prevalence of IBS, which is estimated to affect $12 \%$ of adults in the United States. ${ }^{2}$ However, a plethora of research reports exist regarding the comorbidity of psychiatric conditions and IBS; a MEDLINE search performed in October 2008 revealed 456 citations for the combination of the search terms "irritable bowel syndrome" and "depression." The medical literature shows a strong relationship of IBS with anxiety, chronic fatigue syndrome, and fibromyalgia, as well as depression. ${ }^{3,4}$ The research is sufficiently specific to differentiate a higher frequency of IBS symptoms with panic disorder, generalized anxiety disorder, and major depressive disorder versus social anxiety disorder, specific phobia, and obsessivecompulsive disorder. ${ }^{5}$

There is considerable discussion regarding the role of serotonin in IBS, ${ }^{6}$ which suggests that some antidepressants may be more effective than others. Hayee and Forgacs in their clinical review (2007) presented evidence that (a) the diagnosis of IBS is stigmatized by the method of exclusion, leading to an aura of negativity for the patient; (b) IBS does not have a single cause and is associated with a complex of symptoms; (c) the association of IBS with psychiatric disorders begs the question of cause and effect; (d) despite the reported high prevalence of IBS, many more patients may have IBS who do not consult a physician; and (e) among the antidepressant drugs, the tricyclic antidepressants have been studied most often in IBS, with consistently favorable effects and a number needed to treat (NNT) of $3.2(95 \% \mathrm{CI}=2.1$ 6.5) compared with an NNT of 2.0 for cognitive behavioral therapy and mixed but generally poor results with the selective serotonin-reuptake inhibitors (SSRIs). ${ }^{7}$ Unfortunately, in the present study, Faresjö et al. did not record the subtypes of antidepressants (e.g., SSRIs, serotonin-norepinephrine reuptake inhibitors, or tricyclic antidepressants) reported by the respondents in their population survey.

\section{Choice of Antidepressant}

Amitriptyline has been shown to be effective in adolescents ${ }^{8}$ and adults with IBS, even at a low dose (10 mg per day). ${ }^{9}$ In the meta-analysis performed by Jackson et al. (2000) $)^{10}$ and sum-

\section{FIGURE 1) Rome III Criteriaa for Diagnosing IBS}

Symptoms of abdominal discomfort or pain, for 3 days a month in the past 3 months, associated with 2 or more of the following 3 features:

- Relieved by defecation

- Onset associated with a change in frequency of stool

- Onset associated with a change in consistency (form or appearance) of stool

${ }^{a}$ Criteria fulfilled for the past 3 months, with onset of symptoms at least 6 months before diagnosis. From Longstreth et al. ${ }^{30}$ The complete Rome III diagnostic questionnaire for IBS, including scoring, is available from the Rome Foundation. ${ }^{3}$ IBS=irritable bowel syndrome.

marized by Hayee and Forgacs, 7 of 9 clinical trials of tricyclic antidepressants showed a statistically significant effect with an overall mean difference of 0.9 (95\% CI=0.6-1.2) compared with placebo. ${ }^{7}$ Mertz concluded that tricyclic antidepressants are recommended for moderate-to-severe IBS in which pain is prominent or when other therapies have failed. ${ }^{11}$ Mayer recommends a starting dose of amitriptyline $10 \mathrm{mg}$ at bedtime and gradual dose increases over a period of several weeks to a maximum tolerated dose of not more than $75 \mathrm{mg}$ at bedtime. ${ }^{12}$ In his expert review, Farthing cited psychological interventions (psychotherapy, shortand long-term hypnotherapy, cognitive behavioral therapy) and antidepressants (low and conventional doses) as effective therapies for IBS, including a therapeutic gain of 33\% compared with controls for cognitive behavior therapy. ${ }^{13}$

\section{Diagnostic Uncertainty}

The absence of definitive markers for diagnosis of IBS is not due to a lack of effort. Eriksson et al., for example, studied 80 patients with IBS (30 with diarrhea-predominant IBS [IBS-D], 16 with constipation-predominant IBS [IBS-C], and 34 with alternating IBS [IBS-A]) using 5 psychological and disease-specific scales, a pain score, and biochemical markers (e.g., cortisol, C-peptide). ${ }^{3}$ These researchers found that IBS-D patients, with a higher proportion of males, had less body awareness, fewer psychological symptoms, a better sense of coherence, and higher C-peptide values compared with IBS-C and IBS-A patients who expressed higher body awareness, more depression and anxiety, and an impaired sense of coherence. For managed care, Hayee and Forgacs concluded that the combination of physical and psychological symptoms with high prevalence in IBS makes the primary 
care setting the logical choice for most IBS patients, with referral to therapists with appropriate psychological skills.

\section{More Effective and Safe Drug Therapy is Needed}

Because the diagnosis of IBS is often made by exclusion rather than by definitive markers, it is understandable that pharmacotherapy for IBS is as yet imprecise and still evolving. Camilleri and Chang provide an informative perspective on the opportunities and challenges of bringing new pharmacologic entities to market for a condition that has had many end point markers over the past $10-15$ years. ${ }^{14}$ Mayer (2008) reviewed the drugs and drug classes employed in IBS clinical management, citing only 2 that were approved specifically for IBS: tegaserod (Zelnorm) for IBS-C and alosetron (Lotronex) for IBS-D. ${ }^{12}$ Yet a third drug, lubiprostone (Amitiza), also has Food and Drug Administration (FDA) approval specific to IBS-C (in women aged 18 years and older) and is the subject of a recent JMCP supplement on management of chronic constipation..$^{15}$ The Medical Letter consultants concluded in July 2008 that, for a monthly cost of $\$ 219.88$ for 60 capsules (8 mcg twice daily), lubiprostone "appears to be modestly effective for a small percentage of patients with irritable bowel syndrome with constipation." 16

The 8 randomized, controlled trials for tegaserod show that the active drug was $20 \%$ more likely to be associated with global symptom relief compared with placebo, but with an NNT of $17 . .^{12}$ A Cochrane review by Evans et al. (2007) found no effect of tegaserod on pain or discomfort. ${ }^{17}$ The side effects that became evident with tegaserod, including adverse cardiovascular events, ${ }^{18}$ contributed to the suspension of its marketing in the United States in March 2007; its use was restricted to investigational-drug status in July 2007 for women younger than 55 years who have IBS-C or chronic idiopathic constipation without known cardiovascular problems. ${ }^{19}$

The other promising new chemical entity, alosetron, was approved by the FDA on February 9, 2000, but was withdrawn from the market just 9 months later on November 28, 2000, because of severe adverse effects, including ischemic colitis. ${ }^{20}$ Alosetron was reintroduced to the U.S. market on June 7, 2002, under an agreement between the manufacturer and the FDA, restricted to use only in women with severe IBS-D who have failed to respond to conventional therapy and subject to each patient signing a patient-physician agreement.

The search for a disease-specific drug for IBS has therefore left 2 of the largest brand-name pharmaceutical manufacturers essentially empty handed. A systematic review that is now 8 years old identified 283 studies of IBS, of which 70 met the inclusion criteria, and concluded that the "strongest evidence for efficacy was shown for smooth-muscle relaxants in patients with abdominal pain as the predominant symptom."21 There were 16 studies of smooth-muscle relaxants, such as dicyclomine. The smooth-muscle relaxants have an NNT of 4.5 compared with 3.2 for the tricyclic antidepressants, and both classes are superior to the NNTs for the other 2 classes of drugs: 10.7 for the serotonin4-receptor agonist tegaserod and 7.6 for the serotonin-3-receptor antagonist alosetron. ${ }^{11}$ It is interesting that Faresjö et al. in the present issue of JMCP found that this class of drugs ("motility/ antispasmodics") was used by only $1.7 \%$ of patients with IBS, which is lower than the use rates for other gastrointestinal medications in IBS patients but dramatically higher than in control patients (OR $=22.06,95 \%$ CI-4.43-119.72).

\section{Economic Burden of IBS is Potentially Large}

While the point prevalence of IBS is estimated to be $12 \%$ of adults in the United States, survey data suggest that IBS may affect as many as $20 \%$ of the U.S. population. ${ }^{2}$ But because as few as $10 \%$ of those with IBS report their symptoms to physicians, ${ }^{22}$ the U.S. prevalence rate from administrative claims data ranges from $1 \%$ to $6 \%$ of the population. Data from the National Ambulatory Medical Care Survey from 1997 to 1999 and the National Center for Health Statistics for 1996 show that IBS affected approximately $1 \%$ of the U.S. population, as derived from the primary diagnosis field in medical claims, and accounted for more than 4.4 million physician visits by 2.1 million patients between 1997 and 1999,23 while Everhart and Renault (1991) estimated that IBS accounted for 3.3 million physician visits per year. ${ }^{24}$ More than 20 years ago, Mitchell and Drossman estimated that IBS accounted for $12 \%$ of visits to primary care physicians and $28 \%$ of visits to gastroenterologists. ${ }^{25}$ Talley et al. found that patients with IBS incurred median annual all-cause medical care charges that were $73 \%$ higher than healthy controls without IBS (\$742 vs. \$429 in 1992 dollars). ${ }^{26}$ In a systematic review, Inadomi et al. (2003) found the total economic costs of IBS to be $\$ 1.56$ billion (1998 dollars) in the United States, of which $87 \%$ were direct costs and 13\% were indirect costs associated with absenteeism from work attributable to IBS symptoms. ${ }^{27}$ Hulisz estimated much higher costs of IBS in the United States, including indirect costs associated with lost productivity and adverse effects on quality of life. ${ }^{28}$

Until more specific drug therapies for IBS are available, the mainstay of clinical management is the differential diagnosis to rule out conditions, such as colitis or atypical Crohn's disease, and to present the IBS patient with a model of the disease (e.g., brain-gut disorder) that is plausible, with symptom management of altered bowel habits with either antidiarrheals or laxatives. ${ }^{12}$ Physician acknowledgement of the disease may improve the patient-physician relationship and even result in better treatment outcomes. Dietary modification, such as avoidance of suspected dietary triggers and moderation of fat intake, may be effective in some patients; oral fiber supplementation is widely used but without supporting evidence, and there is a significant placebo effect in IBS that may last 3 months or more. ${ }^{11}$

\section{No Silver Bullet on the Horizon}

In this seeming quagmire of uncertainty in the diagnosis and treatment of IBS, the survey research reported by Faresjö 
et al. in this issue of JMCP was motivated by the hypothesis that nonspecific (and not recommended) drug therapy, particularly acid-suppressive agents, would be high among patients with IBS compared with controls without IBS. What they found is that $15.0 \%$ of IBS patients reported using either prescription (13.3\%) or over-the-counter (1.7\%) acid-suppressive drugs, which is approximately the same absolute proportion (13.3\%) of patients who reported using antidepressants. With 1 in 5 persons potentially affected by IBS, a pharmacologic answer would have an enormous market. On the other hand, Kaptchuk et al. (2008) showed convincingly that IBS is responsive to placebo treatment (sham acupuncture), with significantly greater relief of symptoms, global symptom improvement, and quality-of-life scores when sham acupuncture was combined with augmented patient-practitioner interaction that included active listening, communication of confidence, and positive expectation of patient response..$^{29}$ As noted by other reviewers of the research evidence regarding IBS, ${ }^{7}$ the quote attributed to Hippocrates may be particularly appropriate for this clinical syndrome: "It is more important to know what sort of person has a disease than to know what sort of disease a person has."

\section{Author}

FREDERIC R. CURTISS, PhD, RPh, CEBS, is Editor-in-Chief of the Journal of Managed Care Pharmacy.

AUTHOR CORRESPONDENCE: Frederic R. Curtiss, PhD, RPh, CEBS, Academy of Managed Care Pharmacy, 100 N. Pitt St., Ste. 400, Alexandria,VA 22314.Tel.: 830.935.4319; E-mail: fcurtiss@amcp.org

\section{DISCLOSURES}

The author reports no conflicts of interest related to the subjects or products discussed in this article.

\section{REFERENCES}

1. Faresjö Å, Grodzinsky E, Johansson S, Wallander M, Faresjö T, Timpka T. Self-reported use of pharmaceuticals among patients with irritable bowel syndrome in primary care. J Manag Care Pharm. 2008;14(9):870-77.

2. Drossman DA, Andruzzi E, Temple RD, et al. U.S. householder survey of functional gastrointestinal disorders. Prevalence, sociodemography, and health impact. Dig Dis Sci. 1993;38(9):1569-80.

3. Ericksson EM, Andrén KI, Ericksson HT, Kurlberg GK. Irritable bowel syndrome subtypes differ in body awareness, psychological symptoms and biochemical stress markers. World J Gastroenterol. 2008;14(31):4889-96.

4. Riedl A, Schmidtmann M, Stengel A, et al. Somatic comorbidities of irritable bowel syndrome: a systematic analysis. J Psychosom Res. 2008;64(6):573-82

5. Gros DF, Antony MM, McCabe RE, Swinson RP. Frequency and severity of the symptoms of irritable bowel syndrome across the anxiety disorders and depression. J Anxiety Disord. 2008; Aug 27 (ahead of print).
6. Garvin B, Wiley JW. The role of serotonin in irritable bowel syndrome: implications for management. Curr Gastroenterol Rep. 2008;10(4):363-68.

7. Hayee B, Forgacs I. Psychological approach to managing irritable bowel syndrome. BMJ. 2007;334(7603):1105-09. Available at: www.bmj.com/cgi/ reprint/334/7603/1105. Accessed Oct 25, 2008.

8. Bahar RJ, Collins BS, Steinmetz B, Ament ME. Double-blind placebo-controlled trial of amitriptyline for the treatment of irritable bowel syndrome in adolescents. J Pediatr. 2008;152(5):685-89.

9. Vahedi H, Merat S, Momtahen S, et al. Clinical trial: the effect of amitriptyline in patients with diarrhoea-predominant irritable bowel syndrome. Aliment Pharmacol Ther. 2008;27(8):678-84

10. Jackson JL, O'Malley PG, Tomkins G, Balden E, Santoro J, Kroenke K. Treatment of functional gastrointestinal disorders with antidepressant medications: a meta-analysis. Am J Med. 2000;108(1):65-72

11. Mertz HR. Irritable bowel syndrome. N Engl J Med. 2003;349(22):213646. Available at: http://content.nejm.org/cgi/reprint/349/22/2136.pdf Accessed November 3, 2008

12. Mayer EA. Clinical practice: irritable bowel syndrome. N Engl J Med. 2008;358(16):1692-99.

13. Farthing MJ. Treatment of irritable bowel syndrome. BMJ. 2005;330 (7489):429-30

14. Camilleri M, Chang L. Challenges to the therapeutic pipeline for irritable bowel syndrome: end points and regulatory hurdles. Gastroenterology. 2008 Oct 8 (ahead of print).

15. Eoff JC, Lembo AJ. Optimal treatment of chronic constipation in managed care: review and roundtable discussion. J Manag Care Pharm. 2008;14(9)(suppl S-a):S1-S17. Available at: www.amcp.org/data/jmcp/ November\%202008\%20supplement.pdf.

16. Anonymous. Lubiprostone (Amitiza) for irritable bowel syndrome with constipation. The Medical Letter. Jul 14, 2008;50(1290):53-54.

17. Evans BW, Clark WK, Moore DJ, Whorwell PJ. Tegaserod for the treatment of irritable bowel syndrome and chronic constipation. Cochrane Database Syst Rev. 2007;(4):CD003960

18. FDA-CDER. FDA public health advisory: tegaserod maleate (marketed as Zelnorm). Available at: www.fda.gov/cder/drug/advisory/tegaserod.htm. Accessed May 26, 2007. Information also in The Medical Letter. May 7 , 2007:40

19. U.S. Food and Drug Administration. FDA permits restricted use of Zelnorm for qualifying patients. FDA News. July 27, 2007. Available at: www.fda.gov/bbs/topics/NEWS/2007/NEW01673.html. Accessed October 20, 2008.

20. FDA-CDER. Lotronex (alosetron hydrochloride) information. December 18, 2000; updated May 6, 2008. Available at: www.fda.gov/cder/drug/ infopage/lotronex/lotronex.htm. Accessed October 25, 2008

21. Jailwala J, Imperiale TF, Kroenke K. Pharmacologic treatment of the irritable bowel syndrome: a systematic review of randomized, controlled trials. Ann Intern Med. 2000;133(2):136-47. Available at: www.annals.org/cgi/ reprint/133/2/136.pdf. Accessed October 27, 2008.

22. Talley NJ, Zinsmeister AR, Van Dyke C, et al. Epidemiology of colonic symptoms and the irritable bowel syndrome. Gastroenterology. 1991;101(4):927-34.

23. Kozma CM, Barghout V, Slaton T, Frech F, Reeder CE. A comparison of office-based physician visits for irritable bowel syndrome and for migraine and asthma. Manag Care Interface. 2002;15(9):40-43, 49.

24. Everhart JE, Renault PF. Irritable bowel syndrome in office-based practice in the United States. Gastroenterology. 1991;100(4):998-1005.

25. Mitchell CM, Drossman DA. Survey of the AGA membership relating to patients with functional gastrointestinal disorders. Gastroenterology. 1987;92(5 pt 1):1282-84.

26. Talley NJ, Gabriel SE, Harmsen WS, Zinsmeister AR, Evans RW Medical costs in community subjects with irritable bowel syndrome. Gastroenterology. 1995;109(6):1736-41. 
27. Inadomi JM, Fennerty MB, Bjorkman. Systematic review: the economic impact of irritable bowel syndrome. Aliment Pharmacol Ther. 2003;18:67182. Available at: www3.interscience.wiley.com/cgi-bin/fulltext/118880503/ PDFSTART. Accessed October 31, 2008.

28. Hulisz D. The burden of illness of irritable bowel syndrome: current challenges and hope for the future. J Manag Care Pharm. 2004;10(4):299-309. Available at: www.amcp.org/data/jmcp/Subject\%20Review-299-309.pdf.
29. Kaptchuk TJ, Kelley JM, Conboy LA, et al. Components of placebo effect: randomised controlled trial in patients with irritable bowel syndrome. BMJ 2008;336(7651):999-1003. Epub ahead of print 2008 Apr 3. Available at: www.bmj.com/cgi/reprint/336/7651/999. Accessed October 31, 2008

30. Longstreth GF, Thompson WG, Chey WD, Houghton LA, Mearin F, Spiller R. Functional bowel disorders. Gastroenterology. 2006;130(5):1480-91. 31. Rome III diagnostic questionnaires. Irritable bowel syndrome (IBS) module. Available at: www.romecriteria.org/pdfs/IBSMode.pdf. Accessed October 29, 2008 